\title{
Thermal-electrical Measurement System - a modular, expandable Concept for short-term energy recordings in Buildings
}

\author{
Paul Seidel $^{1 *}$, Joachim Seifert ${ }^{1}$ and Karl Wolffgang ${ }^{1}$ \\ ${ }^{1}$ TU Dresden, Faculty of Mechanical Science and Engineering, 01062 Dresden, Germany
}

\begin{abstract}
In the context of the energy transition in Germany energy-optimized and resource-saving buildings and building systems are being installed. To be able to do this, it is necessary to obtain information from the buildings, such as peak or base load of heating/cooling and electrical consumption. In the following publication a developed short-term analysis system based on a modular non-invasive measurement system will be described. Additional first results from a field test will be presented.
\end{abstract}

\section{Problem context}

The optimized and resource-saving energy supply of buildings represents a challenge in the context of the energy transition in Germany. Therefore, it is desirable that buildings are as efficient as possible and are supplied with a high rate of renewable energies. Unfortunately, these supply structures are currently not found in the building stock, so that a transformation process is necessary. This transformation process must be designed in such a way that the energy supply, consisting of heating / cooling and electrical energy, reaches an optimum.

In existing buildings, important parameters such as peak or base loads are usually not known or are only calculated based on rough assumptions. The consequences are an over-dimensioning of the energy system with lower efficiency and utilization rates. To solve this problem, special tools are needed that allow the determination of the building ore district energy consumption. The following article is intended to present a measurement system for a short-term analysis.

\section{Methodology}

This article will present a modular measurement system, without mechanical intervention in the plant system, a so-called non-invasive system. The system is supposed to take the data of an existing device (e.g., heat pump) and record them in a first step. With these data it is possible to calculate key figures, forecasts and monitoring forward them to a central processing unit. This is done as part of a short-term measurement with a planned duration of three weeks.

In a second step, a long-term forecast is to be calculated from the short-term data, which is the basis for an evaluation of the annual heating consumption. This phase aims to determine which data points and data quantities are required. The third step deals with the optimization of the system technology. Recommendations for energy savings and concepts for a redesign of the system are created.

\section{Measurement system}

The development of the system included the fields of hardware and software. The hardware includes the measurement technology for temperatures, volume flow and electrical power. The main advantage of the measurement equipment is, that it is non-invasive for the plant system. That means, that the measurement system can be installed during the normal operation process. A special installer is not necessary. Additionally, the system consists of a mini-computer (raspberryPI) a small router (with LTE-modem and WLAN) and a LoraGateway. The software for connecting the devices and the data-transfer is written in Python ${ }^{\circledR}$ and was only developed for this application scenario. It can be characterized as follows:

- $\quad$ high modularity

- asynchronous programming

- deterministic storage of the measured data

- high-performance communication between the software-moduls

Due to the strict modularity of the software, it is possible that the same software runs on all measurement-boxes and only one device-specific configuration is necessary. It contains all necessary information about the measuring points, the protocols to be used and the access data.

The developed measurement system consists of four different devices

\footnotetext{
*Corresponding author: paul.seidel@tu-dresden.de
} 
- 1: communication box, hosting the local data service and operates as LoRaWAN [4]Gateway

- 2: electrical box, the measure electrical power with a power converter

- 3: thermal box, heat meter with ultrasonic flow sensor

- 4: additive box to measure temperatures wireless

Figure 1 shows the different devices.

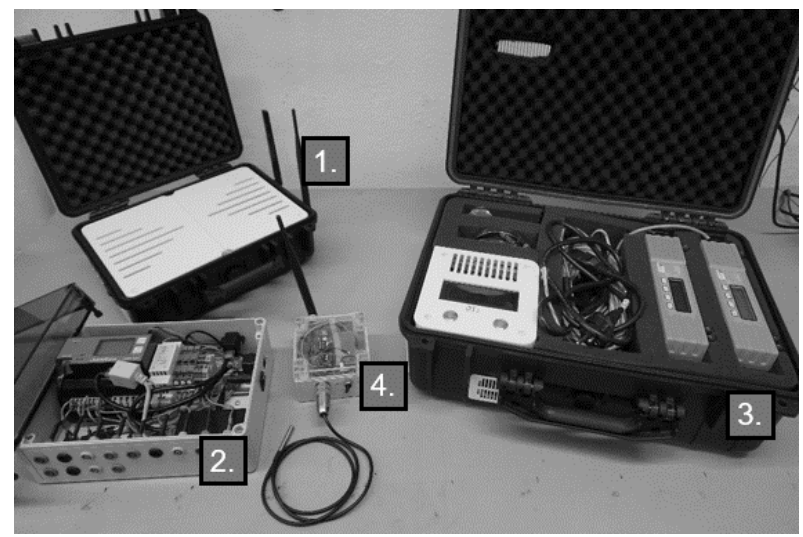

Figure 1. prototype of the modular TEK-EKG measurement system.

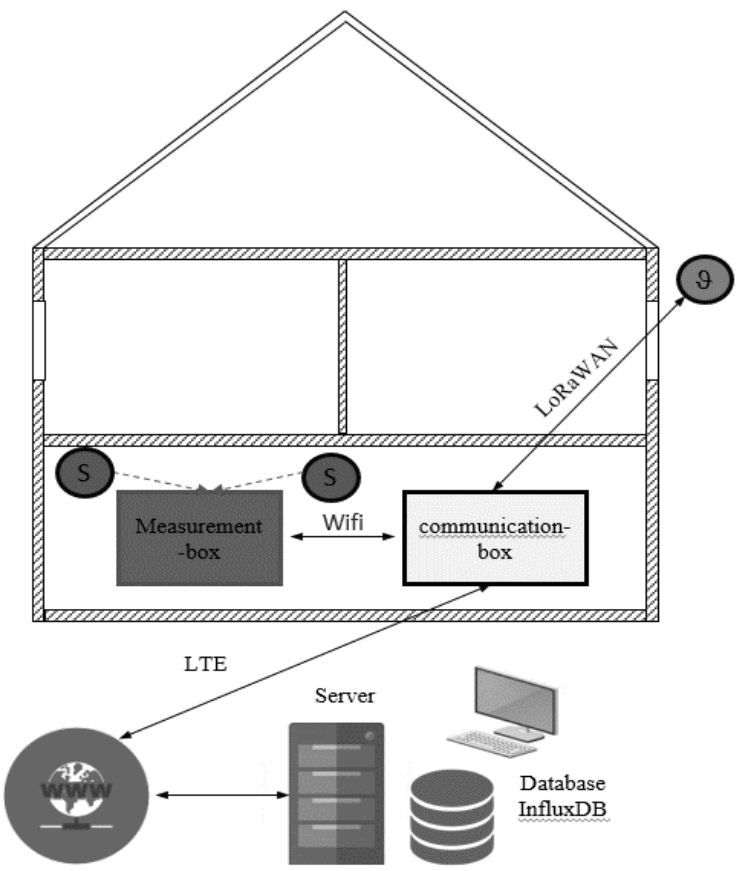

Figure 2. Data-structure of the TEK-EKG measurement and analysis system.

The implemented data structure of the measurementsystem is described in figure 2. The communication protocol between the boxes and the backend based on MQTT (Message Queuing Telemetry Transport) [2].

To save and manage all measured data at the backend, a database for time series, called InfluxDB [3], is used. The main evaluation of the measured data with the developed algorithms is performed in the backend. This includes for example characteristic parameters, operating parameters, forecasts of thermal/electrical demand and a check of the plant control. Additionally, a second database is used for the meta- data of the installed boxes and buildings. In this case, meta-data means e.g. setting parameters of measuring system (ipaddress, kind of box - thermal/electric) and information's of the building (like construction year, window type, heating floor or previous energy consumption). The metadata of the building must be saved to evaluate the measurement data and to derive recommendations for renovations of the plant or building.

\section{Field test}

\subsection{Installation}

The modular TEK-EKG - measurement - system $^{\dagger}$ is installed in different buildings around the tows Hoyerswerda and Dresden in the eastern part of Germany. The installation was carried out in different types of houses (in relation of the type of usage). One building is a typical two-family house with five people and a living space of $A=285 \mathrm{~m}^{2}$. The house was built in 1949 and renovated in the 1970's. The heating system consist of a condensing boiler $(\dot{Q}=44 \mathrm{~kW})$, a thermal storage $(V=4001)$ and a solar thermal system $\left(A=8 \mathrm{~m}^{2}\right)$. In contrast, the two other buildings are used commercial, with a construction year after 2017. The first one is an office building, which is a part of an industrial company with a CHP $(\dot{Q}=80 \mathrm{~kW}, P=50 \mathrm{~kW})$ and a condensing boiler $(\dot{Q}=400 \mathrm{~kW})$ and the second building is a car dealer with a heat pump $(\dot{Q}=45 \mathrm{~kW})$ and photovoltaic system $(P=85 \mathrm{~kW})$ and was build 2020 . For all these buildings the developed measurement system was installed at generation units and at selected heat consumers (for example: underfloor heating, ventilation system). Table 1 shows an overview about the record measuring points.

Table 1. overview of the installed measuring points

\begin{tabular}{|l|l|}
\hline Measuring point & Sensor \\
\hline weather conditions & outside temperature \\
\hline heat pump & $\begin{array}{l}\text { volume flow, flow and } \\
\text { return temperature (heating } \\
\text { side) }\end{array}$ \\
\hline consumer heat circuit's & $\begin{array}{l}\text { volume flow, flow and } \\
\text { return temperature }\end{array}$ \\
\hline domestic hot water & $\begin{array}{l}\text { volume flow, flow and cold } \\
\text { flow temperature }\end{array}$ \\
\hline condensing boiler & $\begin{array}{l}\text { volume flow, flow and } \\
\text { return temperature, gas } \\
\text { consumption }\end{array}$ \\
\hline household, heating system & $\begin{array}{l}\text { electrical power } \\
\text { consumption }\end{array}$ \\
\hline electrical power production: & CHP, photovoltaic \\
\hline
\end{tabular}

†TEK-EKG - thermal- electrical electrocardiogram 
The following evaluation of the results from the field test relates to the building of the car dealer, where the short-term measurement was installed for three months. Therefore, the heating system of this building is presented in more detail (see figure 3 ).

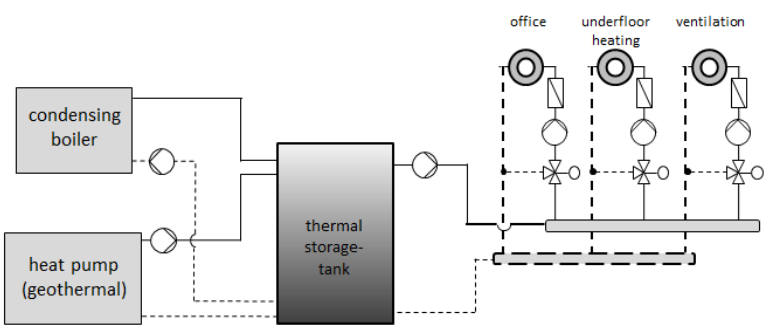

Figure 3. structure of the heating system at the analysed car dealer

The central point of this heating system is the storage tank with a volume of $V=15001$, which connects the two heat generators (heat pump and condensing boiler) and the three heating circuits. The heating circuits are connected to storage tank with a hydraulic switch. It should be noted that the condensing boiler is only installed as a backup with no automatic operation mode. The domestic hot water is generated decentral by electric water heaters.

In addition to the field test in real buildings the measurement system is also installed in a hardware-inthe-loop emulator in the laboratory of the Technical University of Dresden (figure 4). This is necessary to test the system in the re-design phase under development. The focus of these analyses under fixed boundary conditions are the measurement accuracy, a sufficient sampling rate of measurement, the speed and stability of the software, the connection stability, and the range of the wireless sensors. The functionality of each built box was tested and the operations manual, with installed sensor-id's and parameters, was documented.

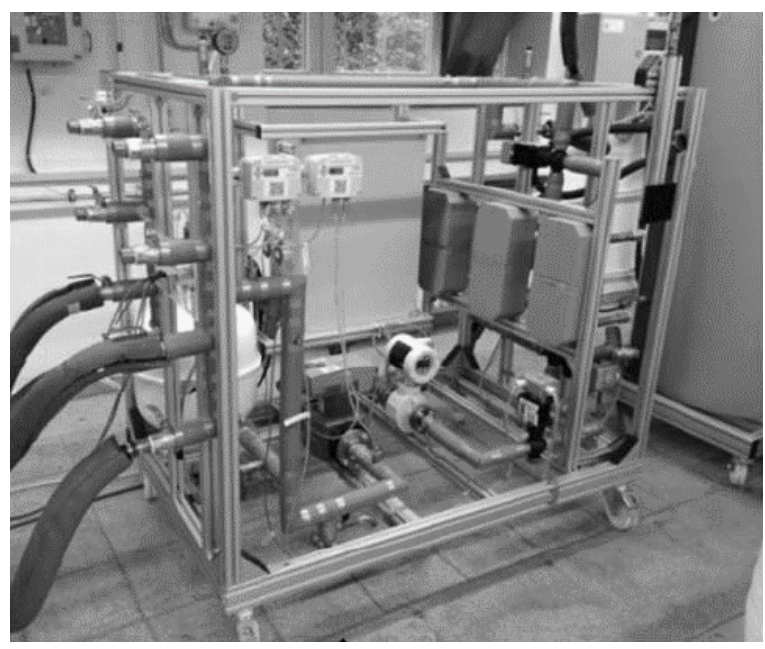

Figure 4. hardware-in-the-loop emulator for testing and development of measurement system at the Technical University of Dresden

\subsection{Test and measurement procedure}

The test and measurement procedure is divided into the two topics: hardware and software/algorithms. The part of hardware includes the operational stability, the correct measurement under different installation positions and the mechanical stability of the cases, cable connectors, batteries, and sensors.

For example, figure 5 shows the installation of the volume flowmeter and different positions of the temperature sensors. Figure 6 also shows the installation of the electrical power meter. By using so called Rogowski coils it is possible to measure the electrical power without direct line contact.
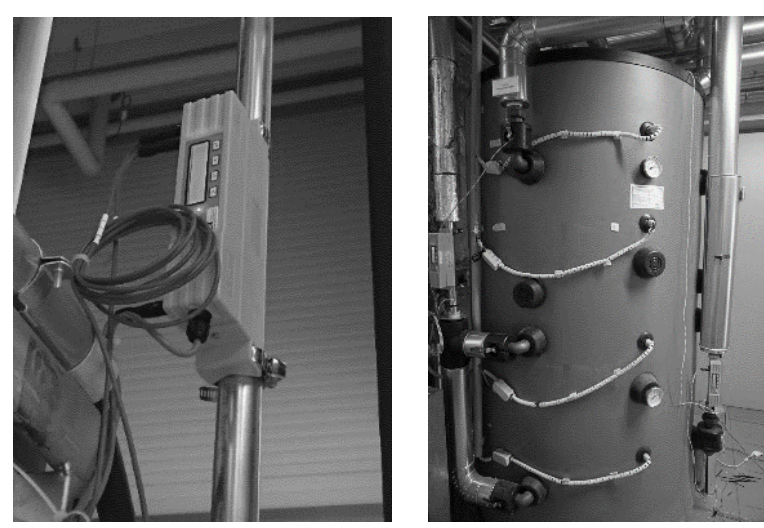

Figure 5. installed heat meter at the analysed car dealer
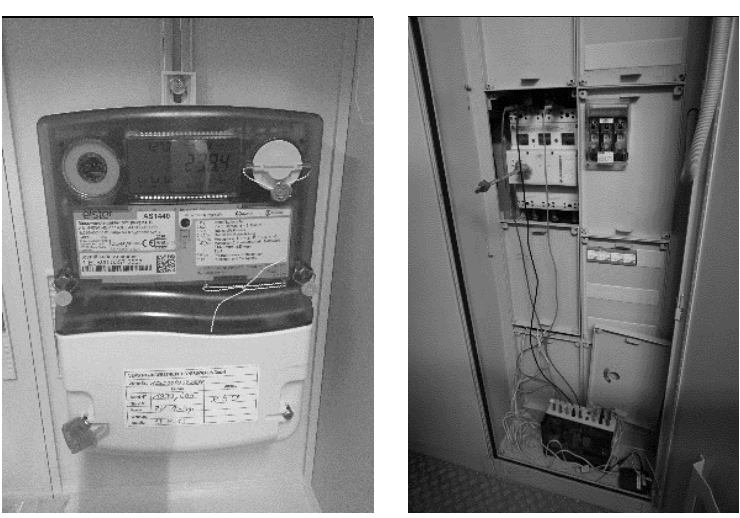

Figure 6. installed electrical power meter at the car dealer

The tests of the software contains on the one hand the error detection in operation, the correct working of interfaces and transmitting the measured data and on the other hand the verifying of the developed algorithms. To check all these points automatically, a platform for online presentation of measured data and calculated key values was created.

\section{Results}

The following chapter present the first results of the field test. Details information can be found in Seifert et. al 2018 [1]. The evaluations focus on the car dealer's building. 


\subsection{Data availability}

During the monitoring of three months, the developed system worked very reliably. The data outages per hour for the time period of October are shown as a heat map in figure 7 .

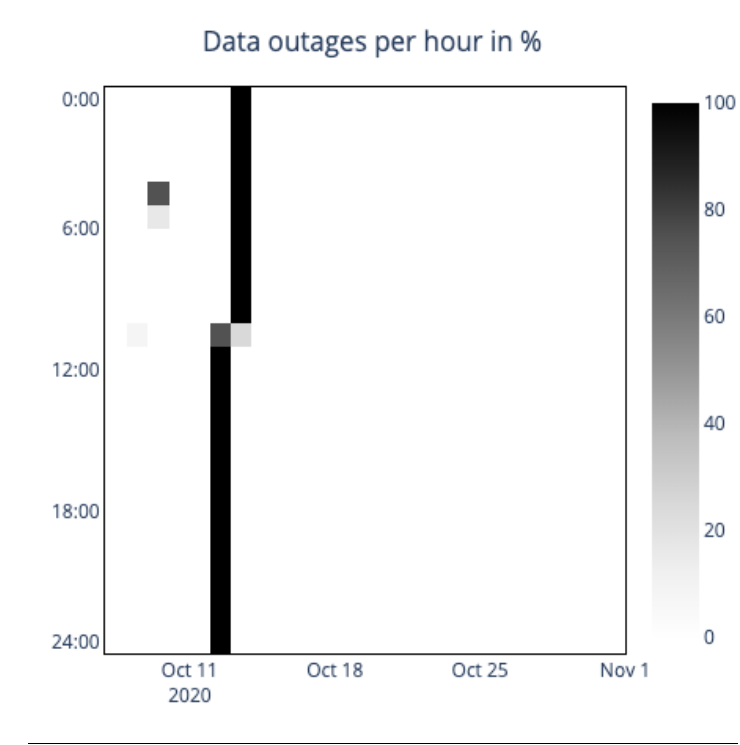

Figure 7. Data outages per hour in $\%$ of all measurement points in october 2020

There was only one major data failure over one day in the beginning of the field test. This problem was due to a connection error of the wireless internet access. A reboot of the central router and developed measurement boxes solved this problem. Other data processing failures were very rare and the consequence of software updates. For Example, this fact is shown in figure 8, with three manual reboots in December 2020

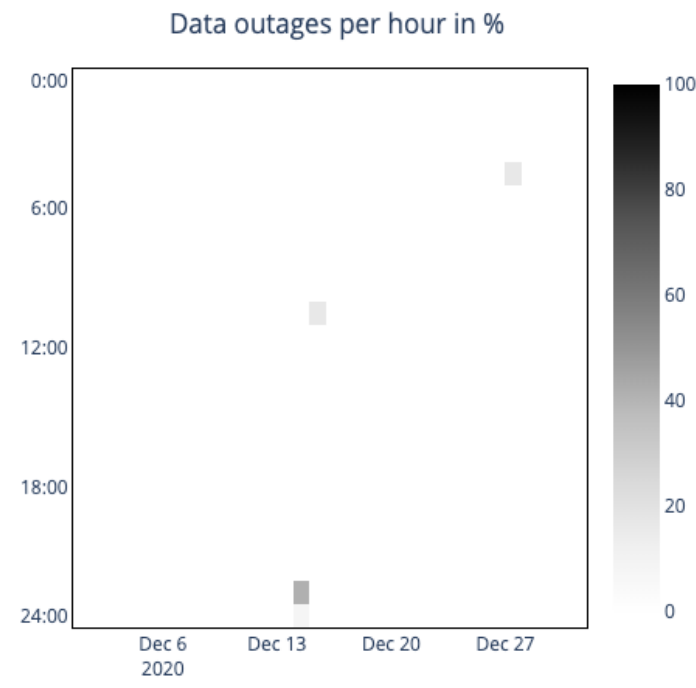

Figure 8. Data outages per hour in \% of all measurement points in December 2020
The error rate of missing thermal data in this time period was $e=1,18 \%$. In addition, there were 13 measurement points (volume flow, temperatures) installed with a sampling rate of 30 seconds. The sampling rate of $30 \mathrm{~s}$ was related to the smallest time constant of the thermal subsystems. The electrical power meter was not considered, because the electrical box was installed later.

\subsection{Characteristic energy values}

The following equations are showing the definition of the efficiency of the installed system consisting of a heat pump. For explanation $\dot{Q}_{H P, t h}$ is the thermal power and $P_{H P}$ the consumed electrical power of the heat pump. $\dot{Q}_{S y s, t h}$ represents the thermal consumers with all heating circuits $\sum \dot{Q}_{H C, t h}$.

\section{heat-pump:}

$$
\begin{aligned}
& C O P_{H P}=\frac{\dot{Q}_{H P, t h}}{P_{H P}} \\
& \beta_{H P}=\frac{\int \dot{Q}_{H P, t h} d \tau}{\int P_{H P} d \tau}
\end{aligned}
$$

\section{heating system:}

$$
\beta_{S y s}=\frac{\int \dot{Q}_{S y s, t h} d \tau}{\int P_{H P} d \tau}=\frac{\int \sum \dot{Q}_{H C, t h} d \tau}{\int P_{H P} d \tau}
$$

The characteristic energy values of the heat pump from 10/2020 -12/2020 is documented in table 2 .

Table 2. thermal/electrical consumption values

\begin{tabular}{|l|l|}
\hline Heat pump values \\
\hline power consumption & $W_{H P}=8,77 \mathrm{MWh}$ \\
\hline heat generation & $Q_{H P}=37,73 \mathrm{MWh}$ \\
\hline efficiency & $\beta_{H P}=4,3$ \\
\hline Building values \\
\hline total power consumption & $W_{H o u s e}=17,8 \mathrm{MWh}$ \\
\hline total Heat consumption & $Q_{S y s}=28,61 \mathrm{MWh}$ \\
\hline heating circuit 1: office & $Q_{H C 1}=4,30 \mathrm{MWh}$ \\
\hline heating circuit 2: selling & $Q_{H C 2}=19,34 \mathrm{MWh}$ \\
\hline heating circuit 3: ventilation & $Q_{H C 3}=5,39 \mathrm{MWh}$ \\
\hline Weather data & \\
\hline mean outside temperature & $\bar{\vartheta}_{\text {outside }}=4,4{ }^{\circ} \mathrm{C}$ \\
\hline
\end{tabular}

During this time period the heat pump reached a efficiency of $\beta_{H P}=4,3$ and the heating system in all a value of $\beta_{\text {Sys }}=3,3$. Since this building is new built, no electrical and thermal consumption values of previous years are available. In relation to an annual view and an 
extrapolation of these short-term data to a year, this building will reach a specific heating value of round about $\mathrm{q}=40-45 \mathrm{kWh} / \mathrm{m}^{2}$.

\subsection{Operating Data}

The main topic of the developed TEK-EKG measurement system is not only to monitoring data. It is the automated determination of key values concerning the building and the plant system. Consequently, it is possible to modelling the thermal/electrical load of a building and to make an assessment of the system.

Therefore, it is necessary to evaluate the limit values of the measured data, for example a maximum of electrical power consumption or of the heat supply. In this study, the values determined are in the range of the system design data or manufacturer information. The TEK-EKG-system measured a maximum thermal power of the heat pump of $\dot{Q}_{H P, \max }=40 \mathrm{~kW}$ and a maximum total thermal power demand of $\dot{Q}_{S y s, \max }=32 \mathrm{~kW}$. During this measurement period the operation mode time of the heat pump was $T=1108 \mathrm{~h}$ and the number of operations was $N=235$. This means that, the heat pump was average $\mathrm{t}=4,7 \mathrm{~h}$ in operation per operation cycle.

Regarding to the electrical consumption, the baseload of the building was $P_{\text {House, } B L}=9,12 \mathrm{~kW}$. This correspond to the $5 \%$ percentile of the measured total electrical power. The maximum value of electrical demand was $P_{\text {House, } \max }=27,31 \mathrm{~kW}$.

Additionally, to the key values, it is possible to get more information about the control and the energy management system of the plant. The Figures 9 and 10 shows the measured supply temperature and return temperature of one heating circuit (selling room with underfloor heating) in relation to the outside temperature. The maximum supply temperature of the system was $\vartheta_{H C \text {, max }}=32^{\circ} \mathrm{C}$ and the heating limit was detected at approximately $\vartheta_{\text {outside }}=10 \ldots 12^{\circ} \mathrm{C}$.

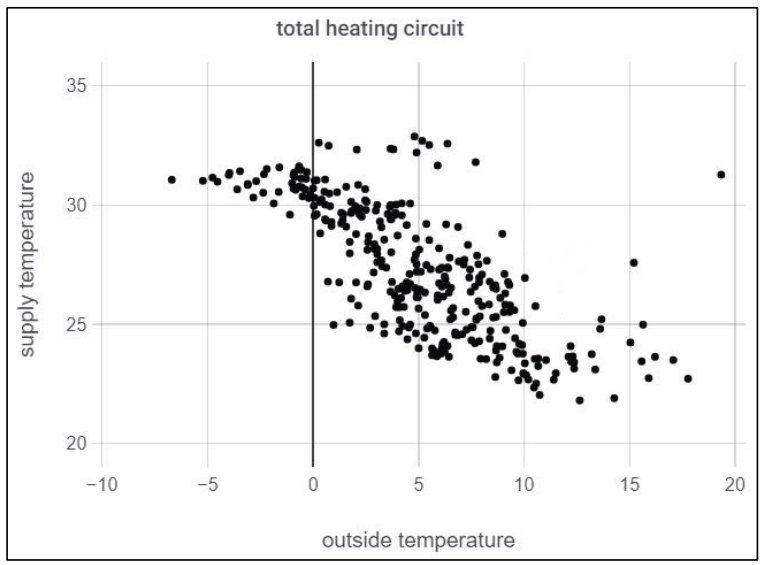

Figure 9. measured supply temperature in relation to outside temperature

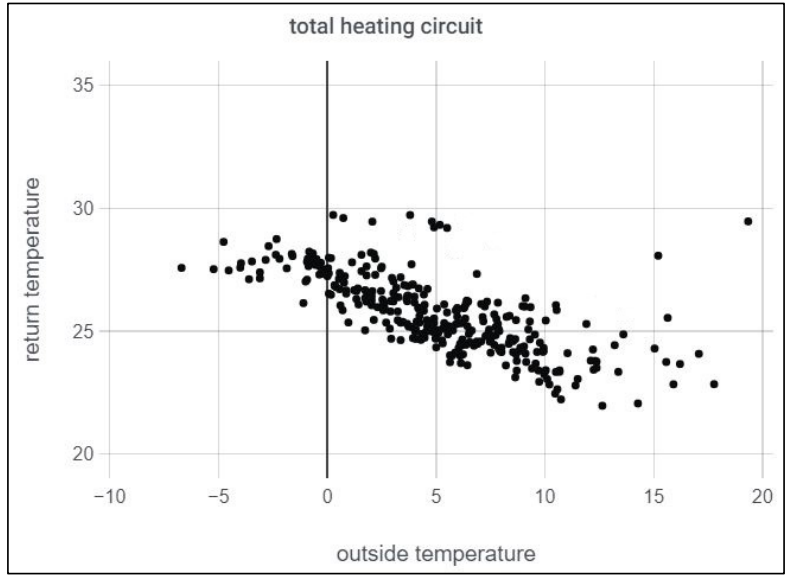

Figure 10. measured return temperature in relation to outside temperature

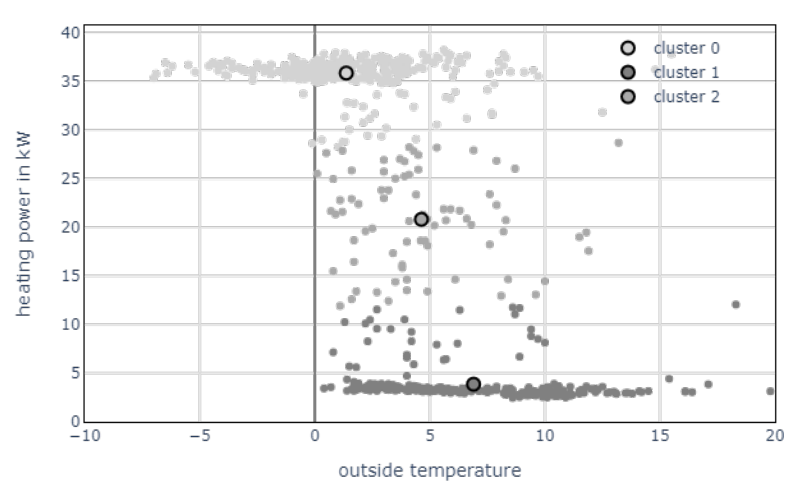

Figure 11. measured heating power (clustered) in relation to outside temperature

Related to figure 11 the light grey points (cluster 0) shows the operation, when the heat pump is on. The dark grey points (cluster 2) show the times when the heat pump system is off. All other points (cluster 1) represent different operating states. If the heat pump is on an almost constant power of $36 \mathrm{~kW}$ is delivered. If the heat pump is of, figure 11 shows that a heat output of $4 \mathrm{~kW}$ was submitted. This is not logical because in situations when the heat pump is off, the heat output must be $0 \mathrm{~kW}$. With the analysis a error in the hydraulic system could be detected.

\section{Conclusion}

During the last 3 years a comprehensive field test of a short-term measurement system was carried out. The main tasks were the development of physical, modular, and non-invasive measurement system and the software development for automatic analysing and failure detection. The central components are a communication gateway/box and measurement boxes which can processed date and sent them to a central backend for further evaluation. This evaluation includes a creation of a load model of the building with the analysed parameters and a thermal / electrical forecast of the annual consumption based on short-term measured data. 
The next future steps deals with the optimization of the energy system technology and control. On the base of the forecast of annual development for different consumers (electricity and heat), recommendations for energy saving and concepts for a redesign of energy systems will be created. The system is robust and can be used reliably.

The advantage of the system presented in this paper is that the basic thermal and electrical behavior of the properties can be detected and analyzed based on a short-term measurement.

\section{Acknowledgment}

This publication is based on a research projects which were supported by the german federal ministry of economics and energy under the code 03ET1478A/B.

\section{Symbols and abbreviations}

$\begin{array}{ll}\text { CHP } & \text { - Cogeneration Heat and Power } \\ \text { CB } & \text { - Condensing Boiler } \\ \text { Sys } & \text { - System } \\ \text { HP } & \text { - Heat Pump } \\ \text { BL } & \text { - base load } \\ \dot{Q}_{H P} & \text { - heat of HP } \\ \dot{Q}_{S y s} & \text { - total heat of heat circuits } \\ \dot{Q}_{H C 1.3} & \text { - heating circuits } \\ P_{H P} & \text { - electrical power - HP } \\ P_{H o u s e} & \text { - electrical power - house } \\ W_{H o u s e} & \text { - electrical energy - house } \\ \vartheta_{i} & \text { - measured temperature i } \\ \beta_{H P} & \text { - utilisation HP } \\ \beta_{S y s} & \text { - total utilisation System } \\ C O P_{H P} & \text { - efficiency HP } \\ N & \text { - number of operations } \\ T & \text { - operation mode time } \\ t & \text { - time } \\ e & \text { - error rate/ failure }\end{array}$

\section{References}

[1] J. Seifert, P. Seidel, K. Wolffgang, M. Potyka et. al., "Thermisch, Elektrisches Anlagen-EKG von Gebäuden und Quartieren" Zwischenbericht, TU Dresden, 2020.

[2] www.mqtt.org

[3] www.influxdata.com

[4] https://www.thethingsnetwork.org/docs/ lorawan/ 